\title{
Herpetic Whitlow: A Case Complicated with Candidemia
}

\section{Canan Özlü $\odot$, Hatice Karaoğlu Asrak $\odot$, Nurşen Belet $\odot$}

\author{
Department of Pediatric Infectious Disease, Dokuz Eylul University \\ of Medical Faculty, İzmir, Turkey
}

Cite as: Özlü C, Karaoğlu Asrak H, Belet N. Herpetic whitlow: A case complicated with candidemia. Trends in Pediatrics 2021;2(3):140-3.

Received: 27 February 2021

Accepted: 09 April 2021

Publication date: 28 September 2021

Keywords: Herpetic whitlow, Herpes simplex type -1, candidemia

Canan Özlü

Department of Pediatric Infectious Disease, Dokuz Eylul University of Medical Faculty, İzmir, Turkey

ORCID: 0000-0002-3749-3078

drcananozlu@gmail.com

\section{ABSTRACT}

Herpetic whitlow is a herpes simplex virus infection of fingers affecting the distal phalanx. The disease is often misdiagnosed as a bacterial infection which leads to inappropriate treatments. In this paper, we reported a case of herpetic whitlow in a 10-monthold girl who is misdiagnosed as bacterial paronychia and treated with surgical intervention and broad-spectrum antibiotics, as a result, she had invasive candidiasis which has a high mortality rate. Physicians should be aware of this entity for correct initial diagnosis and accurate management.

\section{INTRODUCTION}

Herpetic whitlow is herpes simplex virus type- 1 and type-2 (HSV-1 and HSV-2) infection of fingers characterized by painful, nonpurulent, and erythematous lesions usually affecting the distal phalanx. Herpetic whitlow is rare and its' incidence is $2.4 / 100000 .^{1,2}$ It occurs with inoculation of impaired skin with HSV-1 and HSV-2. ${ }^{3-6}$ Because of its rarity, it may be misdiagnosed as bacterial infection, cause inappropriate treatments and complications. ${ }^{6}$

The clinical features of herpetic whitlow should be known by physicians, especially pediatricians, for accurate diagnosis and appropriate treatment. In this paper, a ten-month-old girl who developed candidiasis because of misdiagnosis and inappropriate treatment was described, and the current literature was reviewed.

\section{CASE REPORT}

A previously healthy 10 -month-old girl presented with swelling, redness and discoloration at the distal end of the third finger of her left hand. One week previously her finger became red, vesicular rash appeared on her affected finger (Figure 1) and had a fever for one day. She was admitted to another hospital on the second day after onset of her symptoms, and hospitalized for four days and treated with intravenous antibiotic therapy and two surgical drainage for bacterial paronychia. Then she was referred to our hospital with a prediagnosis of necrosis because of bruising on her finger (Figure 2).

On clinical examination, there were necrotic and erythematous areas in the distal pulp and around the paronychial region of the third finger of the left hand, three vesicles on the lateral side and two incision scars due to the previous surgical drainage 
attempted in bilateral paronychial regions. No pus was observed. Distal pulses were normal. There were no vesiculer lesions in her mouth. Leukocytes: 5400/mcL, ANS: 2300/mcL, Hgb: $12 \mathrm{~g} / \mathrm{dL}$; Plt: $445000 / \mathrm{mcL}$; CRP: $2.1 \mathrm{mg} / \mathrm{L}$, and coagulation parameters were within normal limits. Thrombosis was ruled out due to the presence of vascular flow in both arteries and veins on the Doppler spectral examination of the hand. The $X$ - ray radiogram of fingers was normal. Piperacillin tazobactam and teicoplanin were given with the suspicion of superimposing bacterial infection because of previous hospitalization and two surgical procedures. Intravenous acyclovir was given with suspicion of herpetic vesicles. The molecular tests of vesicle fluid revealed positive HSV-1 DNA. Herpetic whitlow was confirmed and antibiotics were discontinued. Acyclovir treatment was completed to 10 days.

On the eighth day of hospitalization, the patient had a fever. Physical examination did not reveal any focus of infection. Leukocytes: $6700 / \mathrm{mcL}$, ANS: $2100 / \mathrm{mcL}$; Hgb: 11.9 g/dL; Plt: 341000/mcL; CRP: 3.9 mg/L, and urinalysis was normal. Yeast growth was determined in her blood culture taken when she had fever and caspofungin (loading dose of $70 \mathrm{mg} / \mathrm{m}^{2} /$ day followed by $50 \mathrm{mg} / \mathrm{m}^{2} /$ day) was started.

Abdominal ultrasonography, echocardiography and ocular examination were normal in terms of candidal infection. During the follow-up, platelet count decreased $66000 / \mathrm{mcL}$, liver transaminase levels elevated (maximum values were AST: $112 \mathrm{U} / \mathrm{L}, \mathrm{ALT}$ : $75 \mathrm{U} / \mathrm{L}$ ). Blood cultures obtained on the following days of antifungal treatment showed no growth. Fever disappeared on the second day of antifungal therapy. Yeast was typed as C. parapsilosis which was susceptible to caspofungin (MIC: $0.25 \mathrm{mcg} / \mathrm{ml}$ for caspofungin, $0.5 \mathrm{mcg} / \mathrm{ml}$ for fluconazole and 0.25 for liposomal amphotericin B, broth dilution method). Systemic antifungal treatment was continued for 21 days. Thrombocytopenia and elevated liver enzymes returned to normal levels during follow-up. Four weeks after the first herpetic whitlow, vesicular lesions developed in the lateral part of the fourth finger of the left hand which was evaluated as recurrence. Any treatment was not recommended, and the lesion disappeared spontaneously within 14 days without development of any additional complications.
Since immunodeficiency was not considered in the patient's history, an examination for immunodeficiency was not requested.

\section{DISCUSSION}

Herpetic whitlow is an infection characterized by painful, multiple, erythematous non-purulent vesicles formed by HSV type-1 and 2..$^{4,7}$ It was first described by Adamson in 1909 in an adult. ${ }^{8}$ It is characterized by local swelling, erythema and vesicular lesions following the pain and burning after 2-20 days of incubation. In infants, fever and malaise may be present. ${ }^{9}$

Unlike pus in bacterial infections, lesions have clear fluid. But one week later, a cloudy appearance in vesicle fluid may be present due to white blood cells. ${ }^{9}$ In children, herpetic whitlow occurs frequently with autoinoculation or contact between family members if there is herpes stomatitis, herpes labialis, or herpes genitalis. ${ }^{4,7}$ No relevant data were found in our patient's history. The diagnosis of whitlow is usually based on clinical suspicion. In the presence of HSV infection in the patient or close contacts, vesicular lesions on the fingers should suggest herpetic whitlow. The diagnosis should be confirmed by the Tzank test, polymerase chain reaction (PCR) and viral culture from the intravesicular fluid. . $^{1,3,6,10}$ The sensitivity and specificity of the Tzank test is variable depending on the person evaluating it, because of this, recently this test is not preferred. ${ }^{11}$ The diagnosis of our patient was confirmed by the detection of HSV- 1 by PCR from the vesicle fluid.

The clinical course of herpetic whitlow in children was described by Szinnai et al. ${ }^{6}$ In this study, 42 children who were followed up for herpetic whitlow between 1970-2000, the age distribution of patients shows a peak ( $72 \%$ of all cases) particularly in the first 2 years of life and the most common etiologic agent in this age group is HSV- 1 and $65 \%$ of cases were initially misdiagnosed as "bacterial paronychia". ${ }^{6}$ Our case is also in this age group and HSV-1 positive, also bacterial infection was considered at first and incisional drainage was performed twice, like in reported cases. Recurrences were reported $23 \%$ of these children in 2-25 months. ${ }^{6}$ Recurrence was observed in our case four weeks after the first 


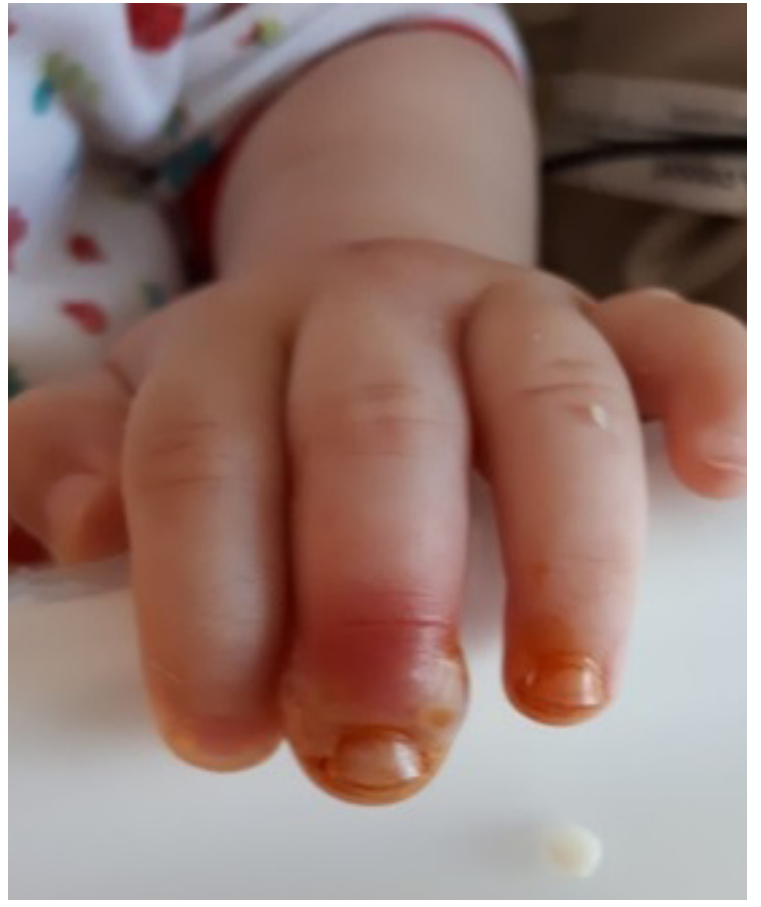

Figure 1. Turbid, yellow and purulent painful vesicles on an intensely ertyhematous base on 1 the medial and lateral side of the third finger episode. No treatment is necessary for healthy children, but some clinicians have reported that systemic treatment reduces the duration of herpetic whitlow. ${ }^{6}$ But systemic acyclovir is indicated for immunosuppressive patients. ${ }^{12}$ The initiation of antivirals within 48 hours of symptom onset results in better outcomes. ${ }^{1}$ Treatment effectiveness of systemic acyclovir, famciclovir or valaciclovir has not been compared, there is no available data. Topical antiviral therapy is not effective. ${ }^{1,13}$ Suppressive therapy with an antiviral agent may be useful for recurrent herpetic whitlow. ${ }^{1}$ Antibiotics should be considered in patients with superimposing bacterial infection. ${ }^{6}$ Surgery is contraindicated because it can lead to the spread of the infection and may result in secondary bacterial infection. The clinical differentiation of bacterial infection and herpetic whitlow is not always easy. Herpetic whitlow is characterized by less pain, clear vesicles at baseline, long and self-limiting clinical course, and nonresponsiveness to antibiotics, with these findings it can be distinguished from bacterial infection. Misdiagnosis may lead to additional infections, serious diseases in immunosuppressed individuals,

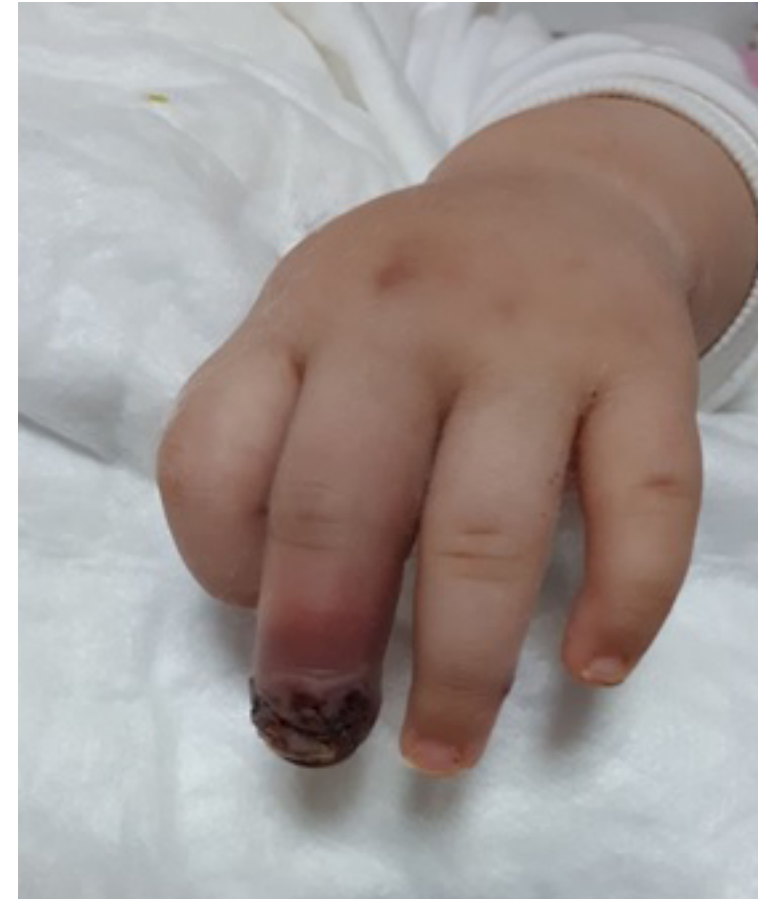

Figure 2. Necrotic areas on ertyhematous base after surgical intervention on the medial and 3 lateral side of the third finger on day 5 of illness

surgery may cause prolongation of recovery and pain, secondary infection and encephalitis. ${ }^{6}$ In our case, due to misdiagnosing, surgical drainage was performed twice and broad-spectrum antibiotics were used because of a possibility of bacterial paronychia. As a result, candidemia developed due to this risk factor.

Candidemia is the fourth most common cause of bloodstream infections. ${ }^{14}$ Colonization with Candida spp., prolonged antibiotic use, presence of central venous catheter, hyperalimentation, long-term hospitalization, previous surgery and intensive care are risk factors for candidemia. ${ }^{15-17}$ In our patient, there was no risk factor other than broad-spectrum antibiotic use. Candidemia was treated with caspofungin successfully. Misdiagnosis and treatment with antibiotics lead to candidemia which has a high mortality rate. Unnecessary surgical drainage and antibiotic treatment due to misdiagnosis led to both hospitalization with increasing cost and lifethreatening infection. In our knowledge, there was no case of candidemia in the herpetic whitlow course. 
In summary, herpetic whitlow should be suspected upon manifestation of clinical signs and diagnosis can be made by PCR and viral culture. The disease is self-limited and surgical interventions should be avoided. Physicians should be aware of this entity for correct initial diagnosis and accurate management.

Conflict of Interest: The authors declared no potential conflicts of interest with respect to the research, authorship, and/or publication of this article.

Funding: The authors received no financial support for the research, authorship, and/or publication of this article.

Informed Consent: Parents of the patient provided informed consent to publish the report.

\section{REFERENCES}

1. Betz D, Fane K. Herpetic Whitlow. 2020 Aug 15. In: StatPearls [Internet]. Treasure Island (FL): StatPearls Publishing; 2021 Jan-. PMID: 29494001. Available from http://www.ncbi.nlm.nih.gov/books/NBK48237

2. Klotz RW. Herpetic whitlow: an occupational hazard. AANA J. 1990;58:8-13.

3. Clark DC. Common acute hand infections. Am Fam Physician. 2003;68:2167-76.

4. Murphy AP, Martin P, Jukka CM, Memon A, Ng SM. Recurrent primary paediatric herpetic whitlow of the big toe, BMJ Case Rep 2013;2013:bcr2013008598. https://doi.org/10.1136/bcr-2013-008598

5. Usatine RP, Tinitigan R. Nongenital herpes simplex virus. Am Fam Physician 2010;82:1075-82.

6. Szinnai G, Schaad UB, Heininger U. Multiple herpetic whitlow lesions in a 4-year-old girl: case report and review of the literature. Eur J Pediatr. 2001;160:52833.

https://doi.org/10.1007/s004310100800
7. Karpathios T, Moustaki M, Yiallourus P, Sarifi F, Tzanakaki G, Fretzayas A. HSV-2 meningitis disseminated from a herpetic whitlow. Paediatr Int Child Health. 2012;32:121-2. https://doi.org/10.1179/2046905511Y.0000000004

8. Adamson HG. Herpes febrilis attacking the fingers, $\mathrm{Br} \mathrm{J}$ Dermatol. 1909;21:323-4.

9. Gill MJ, Arlette J, Buchan AK. Herpes simplex virus infection of the hand. A profile of 79 cases, Am J Med. 1988;84:89-93. https://doi.org/10.1016/0002-9343(88)90013-7

10. Richert B, André J. Nail disorders in children: Diagnosis and management, Am J Clin Dermatol. 2011;12:10112.

https://doi.org/10.2165/11537110-000000000-00000

11. Chayavichitsilp B, Buckwalter JV, Krakowski AC, Friedlander SF. Herpes Simplex. Pediatr Rev. 2009;30:119-30. https://doi.org/10.1542/pir.30-4-119

12. Herpes simplex. In: Kimberlin DW, Bradly MT, Jackson MA, Long SS, eds. Redbook: 2018-2021 report of the committee on infectious disease 31st ed. Itasca, IL: American Academy of Pediatrics. 2018;437-49.

13. Gill MJ, Bryant HE. Oral acyclovir therapy of recurrent herpes simplex virus type 2 infection of the hand, Antimicrob Agents Chemother. 1991;35:382-3. https://doi.org/10.1128/AAC.35.2.382

14. Rentz AM, Halpern MT, Bowden R. The impact of candidemia on length of hospital stay, outcome, and overall cost of illness. Clin Infect Dis. 1998;27:781-8. https://doi.org/10.1086/514955

15. Pittet D, Monod M, Suter PM, Frenk E, Auckenthaler R. Candida colonization and subsequent infections in critically ill surgical patients, Ann Surg. 1994;220: 751-8. https://doi.org/10.1097/00000658-199412000-00008

16. Wey SB. Risk factors for hospital-acquired candidemia, Arch Intern Med. 1989;149:2349. https://doi.org/10.1001/archinte.1989.00390100145030

17. Fraser VJ, Jones $M$, Dunkel J, et al. Candidemia in a tertiary care hospital: epidemiology, risk factors, and predictors of mortality. Clin Infect Dis. 1992;15:414-21. https://doi.org/10.1093/clind/15.3.414 